\title{
Forms of and Factors Associated With Perpetration of Intimate Partner Violence by Men on Their Female Partners Following HIV Status Disclosure in the Ashanti Region of Ghana: A Qualitative Study
}

\author{
Felix Apiribu ${ }^{1,2}$, Busisiwe Purity Ncama ${ }^{1} \&$ Sinegugu Evidence Duma ${ }^{1}$ \\ ${ }^{1}$ School of Nursing and Public Health, College of Health Sciences, University of KwaZulu-Natal, Desmond \\ Clearance Building, Howard College Campus, Durban 4001, South Africa \\ ${ }^{2}$ Department of Nursing, Faculty of Allied Health Sciences, College of Health, Sciences, Kwame Nkrumah \\ University of Science and Technology, Kumasi, Ghana \\ Correspondence: Felix Apiribu, The discipline of Nursing, School of Nursing and Public, College of Health \\ Sciences, University of KwaZulu-Natal, Howard Campus, University Road, Durban 4001, South Africa. Tel: \\ 233-244-968-783. E-mail: fapiribu@yahoo.com
}

Received: November 28, 2019 Accepted: March 19, 2020 Online Published: April 7, 2020

doi:10.5539/gjhs.v12n6p14 URL: https://doi.org/10.5539/gjhs.v12n6p14

\begin{abstract}
Background: Men's experiences of perpetration of intimate partner violence against their female heterosexual partners following disclosure of their HIV positive status is a global health problem. The forms of IPV and factors associated with IPV following the disclosure are under-researched. In this article, we aim to explore and describe the forms of and factors associated with men's experiences of perpetration of IPV against their female partners following the disclosure of seropositive HIV status.
\end{abstract}

Methods: An exploratory qualitative research design using an interpretive phenomenological analysis method was employed for the data collection from participants (men) who perpetrated violence against their HIV positive women. The study setting was done in two HIV clinics in two Hospitals. The study population consisted of all men whose intimate partners had been diagnosed HIV positive and made known to their partners and are seeking healthcare at the two HIV clinics. Purposive sampling technique was employed to recruit participants for the study. An interpretive phenomenological approach was employed for the collection and analysis from eighteen men whose partners had recently disclosed their seropositive HIV status. An interview guide was the tool employed for the data collection. Data collection and analysis were undertaken concurrently.

Results: Most of the participants identified and described the forms of and factors associated with IPV influencing them to perpetrate IPV. Five themes and sub-themes emerged and these include; emotional factors, spousal related factors, Social related factors, Sex-related factors and some forms of IPV which were identified by participants. Each of these themes has subthemes.

Conclusion: Men use different forms of IPV violence in abusing women who disclosure their HIV seropositive status. Several factors as identified in this study accounts for this partner violence. Forms and factors associated with intimate partner violence should be used as a guide in formulating policies and developing a guide that can be utilised in the early detection of IPV in this category of women.

Keywords: forms, factors, HIV, Ghana, seropositive status

\section{Introduction}

Watts and Zimmerman (2002) identified various forms of IPV including physical violence like slaps, punches, and kicks, use of dangerous objects and killings at the home. Some forms of sexual violence were identified which include forced sexual intercourse or sex or being forced to participate in sexual activities that were degrading. Sexual violence is most often followed by emotionally abusive behaviours which include preventing a female partner from visiting or seeing her colleagues or family members, always belittling her or making her feel humiliated, or intimidated; making a woman economically weak by restricting her in economic activities such as not allowing her to work or even taking away her earnings and putting up behaviours in a way that controls her in every aspect of her life (Pinto et al., 2010; Watts \& Zimmerman, 2002). 
Other forms of IPV identified by Li et al (2014) include; physical abuse or violence against women and children, sexual abuse or violence, a mixture of both physical and sexual abuse or violence, and any type of Violence which were related to HIV infection in women. Osinde et al (2011) found in their study inverse relationship between educational statuses of female partners with sexual/psychological abuse whereas a woman's education status may reduce gender inequality and gender-power imbalance in some contexts. Gender inequality and polygamy have been associated with increased risk of IPV (Osinde et al (2011). Osinde et al (2011) also identified violence against women as a key risk factor for people living with HIV/AIDS especially among women.

Several factors are considered when it comes to the violent behaviour of individuals toward other people. In order words, why do we see more violence in some communities and not in others? Violence is a complex phenomenon emanating from some factors including individual factors, relationship factors, social factors as well as cultural and environmental factors. One of the most important steps in the public health approach is how to understand these factors and understanding them is the best way in preventing violence in society (Krug, Dahlberg, Mercy, Zwi, \& Lozano, 2002).

Other factors including biological and demographic factors (Krug et al, 2002) like impulsivity, low educational attainment, substance abuse, and prior history of aggression and abuse are important variables to consider and understand in order to prevent violence in society. According to Pinto et al. (2010), biological factors related to violence perpetration include head injury and neuropsychology; psychophysiology; neurochemistry, metabolism, endocrinology; and genetics. These have to do with the anatomical and physiological imbalance of the body structure and function.

Social norms permitted in society that allow violence in spousal relationships had a positive correlation with women reporting physical and sexual violence perpetrated by husbands against them (Linos, Slopen, Subramanian, Berkman, \& Kawachi, 2013). Krug et al (2002) also identified relations with peers, intimate partners, and family members as factors that increase the risk of violent victimization and perpetration of violence. In the cases of partner violence and child maltreatment, interacting on an almost daily basis or sharing the same home with an abuser may increase the chances of violence in a relationship.

In Sub-Saharan Africa and Ghana in particular, intimate partner violence is a public health and social problem. Some studies (Addo-Lartey et al., 2019; Adomako \& Darkwa Baffour, 2019; Dako-Gyeke et al., 2019; Dery, 2019; Dickson, Ameyaw, \& Darteh, 2020; Fuseini, Afizu, Yakubu, \& Nachinab, 2019; Owusu-Addo et al., 2018; E. Y. Tenkorang, 2019; E. Y. Tenkorang, Asamoah-Boaheng, \& Owusu, 2020) have identified societal, individual and spousal factors as accounting for intimate partner violence perpetration or gender-based violence.

\subsection{The Theoretical Basis of Intimate Partner Violence Perpetration}

According to Pinto et al. (2010), intimate partner violence perpetration has been looked at from varied viewpoints. Bell and Naugle (2008) established theoretical explanations of IPV perpetration after reviewing and critiquing several studies. According to them, feminist theories argue that socially-defined gender roles within patriarchal societies in combination with men's systematic efforts to control women through the use of power and domination are the main causes of IPV. Again, in their view power theorists postulate that violence emanates from within the family and that violence used in resolving family conflicts is learned from childhood when children watch or witness or experience violence perpetration by parents or family members. In addition to this, psychosocial stressors such as power imbalances between spouses increase the risk of IPV. Social learning theories hold that violence develops when individuals model parental behaviour and fail to learn constructive conflict resolution methods. Personality theories emphasize the roles of insecure attachment styles, early childhood family experiences, impulsivity, and borderline, antisocial, and narcissistic traits in IPV perpetration (Pinto et al., 2010).

Even though there is literature about the perpetration of IPV in Sub-Saharan Africa and Ghana (Addo-Lartey et al., 2019; Adomako \& Darkwa Baffour, 2019; Amegbor, Yankey, Rosenberg, \& Sabel, 2020; Apatinga \& Tenkorang, 2020; Baffoe-Whyte \& Sossou, 2019; Cofie, 2018; Dako-Gyeke et al., 2019; Dery, 2019; Dickson et al., 2020; Doat, Negarandeh, \& Hasanpour, 2019; Issahaku, 2015; Owusu-Addo et al., 2018; E. Y. Tenkorang, 2019), no single study has been done with the factors that led to male partners' perpetration of violence against their female HIV positive partners. This study, therefore, seeks to identify and describe the forms of IPV as well as the factors that led to the perpetration of IPV against HIV infected women in Ghana following the disclosure of their HIV statuses. What is also significant in this study is that the data was collected from the perspectives of the perpetrators. 


\section{Materials and Methods}

\subsection{Design}

This study employed a qualitative exploratory design where men answered questions concerning the forms of and factors associated with perpetrating violence against their female HIV seropositive female partners after their HIV seropositive status disclosure. The design was used because little is known about the phenomenon of study in Ghana.

\subsection{Setting}

This study was conducted at two HIV clinics in the Ashanti Region of Ghana. The two HIV clinics served as the link where participants were recruited for the study. The region has the second-highest HIV prevalence rate according to the 2016 sentinel survey. One of the two HIV clinics is located in Kumasi, the Regional Capital of the Ashanti Region of Ghana whilst the other one is a mission hospital located in the Ashanti Akim North district in the same region of Ghana. The HIV clinics serve as referral points for varied people with varied socio-cultural and ethnic backgrounds and from Health facilities within and outside the Ashanti Region.

\subsection{Population and Sampling Technique}

The study population consisted of all men whose intimate partners were diagnosed HIV positive and had disclosed their statuses to their partners and were seeking healthcare at the two HIV clinics. Purposive sampling technique was used in the selection of male participants for this study. Purposeful sampling according to van Wijk et al, (2014) seeks to crystalize the research questions and inquiries, i.e. in choosing participants purposively, "you decide the purpose you want informants to serve and you go out to find some" (Bernard, 2000). Purposeful sampling is based on the assumption that the investigator wants to discover, understand, and gain insight and therefore must select a sample from which the most can be learned (Merriam, 2009).

\subsection{Recruitment Process}

The recruitment process started with visits to the HIV clinics (recruitment link) to see the HIV positive women who came to the clinics for health care and counselling and also for the health workers to assist with the process. It was at this time that we began the process of recruitment of the participants. A preliminary screening using an Abuse Assessment Screening (AAS) tool of the HIV positive women was done to inform the researcher as to whether the female partner has gone through intimate partner violence following disclosure of the HIV status which then informed the decision to contact the male partners. This was done with caution not to give any hint to male partners that their female partners gave out information which could cause more violence in the relationship. Eleven (11) participants were recruited using this method. The HIV clinics were for both men and women and so those men who accompanied their female partners to the clinics or even came to the clinics as patients were also assessed. These men were screened directly to find out if they satisfied the inclusion criteria to be recruited as participants. Seven (7) participants were recruited through this process making a total of 18 participants for this study. Men were recruited to take part in this study if they met the following inclusion criteria: Admit to having been physically violent and/or emotionally, intellectually, sexually or financially controlling of an intimate female partner, had been screened and found to have been abused or have reported an escalation of abuse since disclosure of their (women) HIV status to their partners (men), confessed to having abused their partners following disclosure of HIV status of their partners (women), who voluntarily agreed to participate and potential participants (men) aged 18 years and older and living in Ghana whose intimate partners were HIV positive.

The study also excluded: Those abusive men whose partners indicated that they had access to weapons in fear of endangering their partners, men whose intimate partners were HIV positive and reported to be abusive were excluded if they were very ill and could not speak or if they were in prison and abusive men with a history of mental illness because they may not be in the right frame of mind to answer the questions appropriately

Due to the sensitive nature of the study, participants were reached through the help of health workers in the clinics who provided information once ethical approval was obtained. Women who attended the clinic for health care were screened and asked to inform their partners about the study and the mobile phone number of the research team given to them to give to their male partners to contact the research team if they agreed to participate in the research. Those partners who agreed to participate in the study then called the research team for more details of the research. Potential participants were asked to contact the researcher voluntarily within a week after the screening. After contacts were initiated, the researcher met potential participants. The nature of the study and the requirements of participation were explained to potential participants and if the person agreed to take part, written information about the study was given and written informed consent obtained before the data was collected. 


\subsection{Interviews}

The interview guide developed for the study was based on the study objectives. The authors gave the mobile telephone number of the research team to the female partners to be given to their male partners and to inform and explain to their partners about the study and if they agreed to be part of the study, they were then called by the research team for inclusion. The male partners who accompanied their female partners to the clinics were assessed directly using an abuse assessment screening (AAS) tool and if they were within the inclusion criteria and agreed to be part of the study they were then recruited. In Ghana, HIV clinics are meant for both male and female HIV positive patients. Those males who accompanied their female partners to the clinics or were themselves HIV positive were assessed and included in the study. Seven (7) participants were recruited through this procedure. The consent form was explained to them and made to sign or thump print before starting the interviewing. Individual face-to-face interviews were organized for each participant in a private area or an area of their choice and convenience. Interviews were conducted in English or Twi based on the preference of the participant because most of the people in these settings speak either English or Twi or both. Each interview was voice-recorded and transcribed verbatim. The interviewer (main researcher) asked probing questions to elicit further and more nuanced descriptions of participants' knowledge of the forms and factors associated with IPV. In these interviews, more specific questions were asked. The interviewer was attentive to and encouraged participants to express their own opinions. The interviews started with an introduction of the interviewer and a short repetition of the study's aim and objectives as well as participants' rights. Before responding to the broader questions aiming at narrative answers, participants were asked to provide background information regarding IPV. Interviews were conducted in the participants' place of choice. Each interview lasted between 60 and 90 minutes (one and a half hours). Pauses and various emotional expressions were documented. Besides, the interviewer documented 'silent' data that were considered important, such as facial expressions, gestures, and actions, in field notes during the interview. These field notes were considered during data analysis as part of the context of the text. Transcription was done within 24 hours after the interviews. This allowed the repeated reading of transcripts to make meaning of participant's accounts. Transcribed data were analyzed concurrently by thematic analysis using the NVIVO 12 software. All interviews were voice recorded with the permission of participants and the data transcribed verbatim from Twi to English if it was done in Twi and each participant was assigned a pseudonym to ensure anonymity.

\subsection{Data Analysis}

The authors used the Diekelmann, Allen, and Tanner's (1989) methodological process of analysing narrative text to guide the data analysis. The analysis was done by reading the interviews to obtain an overall understanding; writing interpretive summaries and coding for emerging themes; analysing selected transcripts as a group to identify themes, and returning to the text or to the participants to clarify disagreements in interpretation and writing a composite analysis for each text. We also compared and contrasted the texts to identify and describe shared practices and common meanings; identified patterns that link the themes; and elicited responses and suggestions on the draft from the interpretive team and from others who are familiar with the content or the methods.

This was accomplished by;

a) Reading and rereading each transcript and working up cases to isolate repetitious themes; and

b) Identifying exemplary quotes to illustrate themes.

The qualitative raw data were transcribed verbatim and discussed. Audiotapes of interviews in the English language were transcribed directly. However, those that were in the local dialects (Twi) were first translated into the English language by a language consultant. Using Microsoft Word processor, the transcripts were all typed and converted into a text-based electronic format and saved as separate files. Finally, by using NVivo 12, a qualitative data analysis software, a new project was then created and all files imported for processing and analysis.

\subsection{Trustworthiness/Rigor}

Methodological rigour has to do with the issue of quality in research (Brink, Walt, \& Rensburg, 2012; Pereira, 2012). It is the strictness or firmness with which trustworthiness is addressed. To ensure the truthfulness and trustworthiness of the data, a consistent approach for all the participants was used. The true value of information was reported and cross-checked by supervisors and knowledgeable colleagues (member check). In this study, faulty or ambiguous wording of questions was avoided by a pilot test. During the interview, the personal characteristics of the participants were considered. Any time respondents were fatigued, interviewing stopped. Coding errors such as missing data and incorrect recording were avoided by reading and rereading audiotapes and cross-checking of details. A diary was kept in which the researcher's feelings, initial insight into coding and potential biases were recorded; this kept the researcher true to the details of the data collected. To improve rigour, 
there was respondent validation, clear detailing of methods of data collection and analysis. This was done by the process of detail reports and sampling techniques.

\subsection{Ethical Consideration}

Ethical clearance was obtained from the University of KwaZulu-Natal Biomedical Research Committee (BREC REF: BF629/18), South Africa and the Committee on Human Research, Publications and Ethics (CHRPE /AP/572/18) at the Kwame Nkrumah University of Science and Technology (KNUST) before data collection. Participants were provided with an informed consent form to sign after it was explained to them. As a policy of the Ministry of Health in Ghana, all primary, secondary and tertiary hospitals are provided with clinical psychologists. The researcher solicited the services of these clinical psychologists in each of the study settings to help in the psychotherapy of research participants whose traumatic experiences were reactivated.

\section{Results}

\subsection{Participants' Characteristics}

Table 1. Participants' background characteristics

\begin{tabular}{|c|c|c|c|}
\hline & & Frequency & Percentage (\%) \\
\hline \multirow{3}{*}{ Age } & Less than 40 years & 13 & 72.2 \\
\hline & $41-50$ years & 3 & 16.7 \\
\hline & 51 years and above & 2 & 11.1 \\
\hline \multirow{3}{*}{ Age of spouse } & Less than 40 years & 16 & 88.9 \\
\hline & $41-50$ years & 1 & 5.5 \\
\hline & 51 years and above & 1 & 5.5 \\
\hline \multirow{4}{*}{ Educational level } & Primary & 4 & 22.2 \\
\hline & JHS/middle & 10 & 55.6 \\
\hline & SHS & 2 & 11.1 \\
\hline & Tertiary & 2 & 11.1 \\
\hline \multirow{2}{*}{ Religion } & Christian & 15 & $83.3 \%)$ \\
\hline & Muslim & 3 & $16.7 \%$ \\
\hline \multirow{4}{*}{ Occupation } & Trader/business & 10 & 55.6 \\
\hline & Farmer & 3 & 16.7 \\
\hline & Beer bar operator & 2 & 11.1 \\
\hline & unemployed & 1 & 5.5 \\
\hline \multirow{4}{*}{ Marital status } & Married & 7 & 38.9 \\
\hline & Divorced & 8 & 44.4 \\
\hline & Separated & 2 & 11.1 \\
\hline & Widow & 1 & 5.6 \\
\hline \multirow{4}{*}{ Length of marriage } & Less than 1 year & 5 & 27.8 \\
\hline & $1-2$ years & 5 & 27.8 \\
\hline & 3-4 years & 6 & 33.3 \\
\hline & 5 years and above & 2 & 11.1 \\
\hline \multirow{2}{*}{ HIV status } & Negative & 5 & 27.8 \\
\hline & positive & 13 & 72.2 \\
\hline
\end{tabular}

The majority of participants and their partners were in youthful ages with most of them having low educational levels. Participants were either married, divorced or separated. Most of the participants were in their relationship 
for about 6 years or less. The majority of the participants had a concordance infection. Only $5(27.8 \%)$ had a discordant infection. See table 1 above for more detailed information about the participants' background characteristics.

\subsection{Factors Associated With Perpetration of IPV}

The objective of this study was to explore and describe the factors associated with the perpetration of IPV by men who perpetrated violence against their HIV positive female partners following the disclosure of the seropositive HIV status. We interviewed men to explore their views on the different forms of IPV and the factors that contribute to the perpetration of violence. Most of the participants identified and described the forms and factors of IPV as influencing them to perpetrate IPV. Five themes and sub-themes emerged as seen in table 2 below.

Table 2. Themes and sub-themes generated

\begin{tabular}{|c|c|}
\hline Emotional factors & $\begin{array}{ll}\text { - } & \text { Anger and Frustration } \\
\text { - } & \text { Fear of death and rejection }\end{array}$ \\
\hline Spousal-related factors & 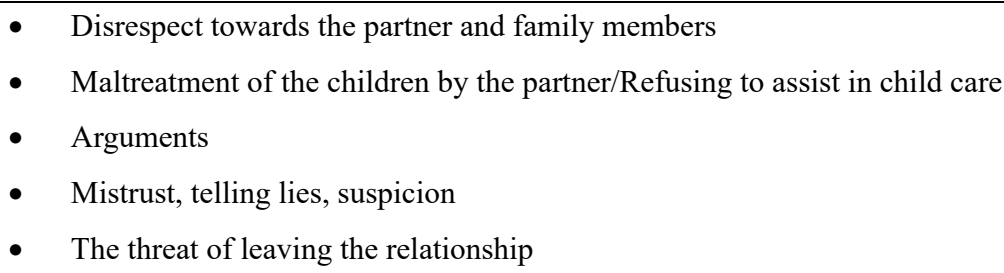 \\
\hline Social-related factors & $\begin{array}{ll}\text { - } & \text { Norms and taboos } \\
\text { - } & \text { Peer influence } \\
\text { - } & \text { Alcohol, drug abuse } \\
\text { - } & \text { Poverty and male domination }\end{array}$ \\
\hline Sex-related factors & $\begin{array}{l}\text { - } \\
\text { - } \\
\text { - } \\
\text { - } \\
\text { Porcing to have sex with a partner } \\
\text { Prending to be sick to avoid sex and flirting }\end{array}$ \\
\hline
\end{tabular}

Forms of intimate partner violence

\section{Theme 1: Emotional factors}

This theme was the major one as revealed by participants. Several subthemes emerged from this theme and these include anger and frustration as well as fear of death and rejection.

\section{Anger and Frustration}

Anger and frustration were identified as the main factors of violence as revealed by most of the participants. This was supported by the statement by participants when one of them said.

The factors that bring about violence are when your partner makes you angry and frustrated and then you have the feeling that you are being rejected, it can lead to violence (Yakubu, 50yrs old, married, $+v e$ ).

Again, Salifu identified anger, hatred, and neglect as some factors that can lead to abuse of one's partner.

The causes of these abuses are anger, hatred, and neglect (Salifu, 40yrs old, divorced, $+v e$ ).

Another participant in trying to stress that sadness and anger were the main causes of the violence said.

So when your partner becomes angry and looks at you with bad feelings is a factor that can make you abuse her (Dwomo, 31yrs old, married).

In a related extract, this participant said this.

When the condom burst I became angry at that instance and became violent towards her. So anger from either the male partner or female partner can lead to violence (Kofi, 36yrs old, separated). 
Salid, 39 years old stated that he was so angry that he verbally abused his wife.

I was angry with her and so I told her she was a devil and wanted to kill me. The anger was the cause of the abuse (Salid, 39yrs old, married).

\section{Fear of death and rejection}

It was revealed in this study that for fear of death participants did things that hurt their partners. Some of the participants felt they were going to die and so reacted so badly towards their female partners by abusing them. This is what Baba, a 31-year-old divorcee, said.

I knew she was going to die............. I thought I was condemned to death because of my previous knowledge of the condition and so I started abusing her (Baba, 35yrs old, divorced).

Emotionally, participants fear that they were going to die and this made them vent their anger on their partners.

I had sleepless nights thinking of what to do with my life now that I am condemned to death. Because of the fear of death and the fact that I felt she infected me, I abused her (Dwomo, 31yrs old, married).

Another participant also said this:

That time I thought I had finished, I thought I was even dead. This led to fights among us (Naba, 36yrs old, separated).

\section{Theme 2: Spousal-related factors}

\section{Disrespect towards the partner and family members}

Respect is a virtue every man will need from the partner. Some of the participants identified disrespect by the partner as one of the factors that will make them abuse their partners. Yaw stated his view this way:

You must respect your husband always no matter what. Disrespect to me is the cause of IPV (Yaw, 65yrs old, married 2 wives).

Salifu, a 40-year-old man, also said the partner must respect him or else there will be divorce and indeed he divorced the wife. This is what he said.

As a man, you must respect me and because of disrespect and other issues, I divorced her (Salifu, 40yrs old, divorced).

\section{Maltreatment of the children by the partner/Refusing to assist in child care}

Failure to assist in taking care of the children in relationships was identified as one of the factors that led to intimate partner violence. Salifu said partners refusing to help in taking care of the children can lead to fights or it may bring violence among couples. He puts his views this way:

One of the factors is when you refuse to help your spouse in taking care of the children (Salifu, 40yrs old, divorced).

When a partner or partners refuse to help in taking care of the children in relationships, it can lead to violence in the family. Dwomo said this can lead to violence against the partner.

She may even start maltreating the kids which will make you react negatively against her by refusing to help her take care of the kids or even beat her or shout at her (Dwomo, 31yrs old, married, -ve).

Adama also identified refusal to help with household chores and not allowing the other partner to have access to the children as being some factors that can lead to violence in intimate partner relationships. He said;

Some of the factors of violence can also be refusing to help with household chores or not allowing the other partner to have access to the children (Adama, 40yrs old, widowed, +ve).

\section{Arguments}

Some of the participants revealed that their partners instead of feeling remorseful rather argued with them which led to fights. Kwabena, a 62 years' old married man, said:

I beat her because she thought she knows more than me and is always arguing with me. The argument was the factor that made me beat her (Kwabena, 62yrs old, married).

One of the participants was so furious with the wife because she was arguing with him. This made him divorce her. This is what he said.

I had to insult and ignore her in whatever I was doing because instead of her feeling remorseful, she was still 
arguing with me. I think arguing with me was the factor that made me to abuse her (Dwomo, 31yrs old, married).

\section{Mistrust, telling lies and suspicion}

The mistrust of a partner was identified as the cause of violence. This is what Kofi said.

The causes are hiding the truth, lack of trust and suspicion (Kofi, 36yrs old, divorced, -ve).

Again, one of the participants identified suspicion of the partner of unfaithfulness as one of the factors that will cause one to abuse the partner. This is the statement made by Baba, a 35-year-old man, also HIV positive:

The factors that cause this violence include suspicious of unfaithfulness (Baba, 35yrs old, divorced, +ve).

Some of the participants identified mistrust and lies as the factors that influence intimate partner violence. Salid put his this way.

The factors that cause abuse are mistrust and lies (Salid, 39yrs, married, +ve).

Telling lies or hiding the truth was identified by some of the participants as a factor that led to abuse. Dwomo stated that when a partner refuses to tell the truth it hurts and can lead to abuse. He said:

Some of the things that make people maltreat their partners are because sometimes the partners refuse to tell the truth and this hurts. This makes their partners react negatively and can cause harm to their partners by beating them or divorcing or sacking them from the home (Dwomo, 31yrs old, married, -ve)

\section{The threat of leaving the relationship}

The threat of leaving a relationship is one of the factors identified as being the reason for the perpetration of intimate partner violence on a partner. This was made clear when this participant stated:

We used to fight but not the exchange of beatings because most of the time I am always quiet because she was most of the time right but as a man, I don't want to agree to her advice. What led to me abusing her was because she threatened to leave me for another man (Naba, 36yrs old, separated).

Another participant in an effort to state his views in relation to the threat of leaving the relationship said.

She said she will leave the relationship because I am not treating her well and because of her HIV status. She said she wants a divorce from me so that we will not be partners again but I didn't take this lightly and started maltreating her (Kojo, 37yrs old, divorced).

Adama also added that when a partner tells you she is leaving the relationship for no reason or even she who has caused the problem is still saying she will leave the relationship causes one to react with violence.

Trying to leave the relationship without the agreement of your partner can lead to violence (Adama, 40yrs old, widowed, +ve).

\section{Theme 3: Social related factors}

Some social factors also accounted for intimate partner violence. Most of the factors identified by participants include norms and taboos, peer influence, alcohol, drug abuse

Poverty and male domination.

\section{Norms and taboos}

Most of the participants identified certain cultural practices as being the cause of intimate partner violence. Participants stated that the cultural norms and taboos of their cultures did not allow women to challenge their partners and so if it happens it creates room for abuse. Adamu, 39 years old stated his views as:

Some cultures have the men as the head and the woman has no say. So whatever he wants must be done without questions. Just obey and be free is the rule..........It also goes against the customs of some tribes like mine....

It is a taboo to our customs here and the woman must be divorced or even be beaten and thrown out of the house if they disobey their husbands (Adamu, 39yrs old, divorced).

Cultures where age is respected, women who are usually the younger in the relationship are victims of abuse if they don't obey the husband. This is what he said.

I think I am the older person and so when she is angry she shouldn't talk the way she does to me because we respect age here.............. In our society here women respect men so if I talk and you also talk as if you are a man it can make me angry and I will beat you or insult you or even sack you from my house.............our culture also makes us feel we are the big people and so we should not be challenged (Salifu, 40yrs old, divorced, +ve).

Salifu also identified violation of some norms of the family as well as the feeling that the infection has brought 
shame and disgrace to the family as the cause of violence and so are factors that cause intimate partner violence in relationships.

When you think she has brought shame and disgrace to the family and when her behaviour is contrary to the norms of the family are factors of abuse(Yakubu, 50yrs old, married, $+v e)$.

\section{Peer influence}

Some of the participants identified peer influence as one of the factors that can lead to violence in intimate partner relationships. Kweku supported this by saying.

So I decided to drink because already I used to drink with my friends. So I drink alcohol because of friends and enjoyment and they tell me how they treat their partners which influenced our relationship negatively. So peer pressure is a factor in abusive relationships (Kweku, 40yrs old, married, +ve).

Kwabena, a 62-year-old man, also said among other factors, peer influence can make one abuse the partner.

Several factors can lead to abuse. Anger, frustration, alcohol intake, drugs, and peer influence as well as fear of rejection by society because your wife is HIV positive (Kwabena, 62yrs old, married, -ve).

\section{Alcohol, drug abuse}

Most participants identified alcohol, drug abuse, and poverty as factors that cause violence in relationships. Kwabena stated it like this.

I drink from time to time........... Sometimes when we drink we can also become high and abuse our partners. So alcohol is a factor in intimate partner violence (Kwabena, 62yrs old, married, -ve).

Papa, a 33-year-old man and also HIV positive also said:

As for the drink I used to take. As of now because of the thinking I sometimes take alcohol and when I take it I go to fight my wife. I believe alcohol is the factor for the abuse (Papa, 33yrs old, married, +ve).

Some participants also stated that when their partners told them about the HIV status, they started drinking. They will drink and come home to fight with their partners. They feel alcohol was the factor that escalated the abuse. Yakubu stated his view this way.

I used to drink and come to beat her. I was not smoking but I used to drink so that it will help me stop thinking. I think alcohol is one of the factors that make me abuse my wife (Yakubu, 50yrs old, married, +ve).

Kweku, a 40-year-old married man, also said.

I drink alcohol because of friends and enjoyment and they tell me how they treat their partners which influenced our relationship negatively. The alcohol had made me abuse my partner. So alcohol is also a factor in abusive relationships (Kweku, 40yrs old, married, +ve).

\section{Poverty and male domination}

In some cultures men control and dominate their partners. In this study, participants identified poverty and dominance as one of the factors that lead to violence in relationships. Baba, 35 years old, stated that the man is the head in the relationship and as such controls everything.

Sometimes we want to prove that we are the men of the family and as such should not be challenged. We control and dominate everything in the marriage (Baba, 35yrs old, divorced).

One participant also identified disobedience as a way of trying to weaken his control of the woman. When this happens, it can also lead to violence against the woman. It is a way of dominating the woman. These, when not followed by the woman, can lead to violence. This is what Dwomo said.

I am the man and she has to obey me and do what I want. So she should be obedient to me so that there will be peace in the family. When she doesn't do this it means she cannot be controlled and wants to take over the place of the man and as a man, I will not agree to that. So we use force to make sure she is controlled (Dwomo, 31yrs old, married).

Kojo also said that the woman in the relationship is $100 \%$ controlled by the man. So when the woman is fully for the man, it means she is under the control of the man. This allows the man to dominate over the partner. This is what he said.

The lady is someone who is $100 \%$, she is $100 \%$ for me. So her life and activities in the family should be controlled by the man (Kojo, 37yrs old, divorced). 
Yakubu, 50 years old, also said this in support of the fact that control and domination lead to violence and so is a factor that causes violence in relationships.

As a man, I am the head of the house and so I will not allow a woman with weak morals to come and spoil our dignity in the family. This is a shame and disgrace to our ancestors and the spirit world. I will not accept it (Yakubu, 50yrs old, married).

Poverty was also identified as one of the factors that can lead to violent behaviour as well as male dominance. Salifu stated that when you are poor you tend to be violent towards your partner. This is what he said.

Poverty makes a man violent towards his partner. So poverty is one of the factors that can lead to violence in relationships (Yaw, 65yrs old, married 2 wives, + ve).

Baba, a 35-year-old man, also identified male dominance as a factor for intimate partner violence. He said:

Sometimes we want to prove that we are the men of the family and as such should not be challenged. This can lead to violence in the family (Baba, 35yrs old, divorced, +ve).

\section{Theme 4: Sex-related factors}

Sex is an important factor when it comes to family life, especially with an intimate partner. In line with this, refusing to have sex with one's partner, forcing to have sex with the partner, Suspicion of unfaithfulness and pretending to be sick to avoid sex were identified as factors that led to violence in the family.

\section{Refusing to have sex with a partner}

Most participants said they were violent towards their partners because they refused to have sex with them. They stated that one of the factors that can make one abuse the partner is a refusal of sex. This is what one said.

Some of the things that make men abuse the partners are a refusal to have sex with him. As a man, you control everything including the choice to have sex with your wife and so she must allow you to have your way. When the man also refuses to have sex with the woman it can bring problems in the marriage.......... You can't be in a marriage and go round having sex with other men....... As a man, you control everything including the choice to have sex with your wife and so she has to allow you to have your way........... So refusing to have sex with your partner is a factor for violence to occur (Adamu, 39yrs old, divorced, +ve).

Baba, a 35-year-old divorcee also said.

One factor that can cause abuse is a refusal to have sex with your partner which can cause negative reactions from men (Baba, 35yrs old, divorced, +ve).

The belief that in marriage, there cannot be a refusal of sex leads to violence if the woman refuses her partner sex. Salifu said.

I have sex with my wife at any time I want because I am a man and you can't say you won't allow me to do it. If you try there will be a fight. So refusing to have sex with your partner is a factor in abusive relationships (Salifu, 40yrs old, divorced).

\section{Forcing to have sex with your partner}

Forced sex in relationships can lead to violence. Some of the participants identified forcing to have sex with a partner as one of the factors leading to intimate partner violence in relationships. Adama stated his this way.

Forcing to sleep with a partner or even refusing to sleep with them is a factor that can lead to violence in relationships (Adama, 40yrs old, widowed, + ve).

\section{Pretending to be sick to avoid sex and flirting}

Sex in intimate partner relationships is very important and when this is denied for any reason, it is a factor for violence in the relationship. This point was made clear when Adamu, a 39-year-old man and also HIV positive said;

Pretending you are sick when you are not in order to avoid sex, flirting with other men and doing those things that your man doesn't want are some factors that lead to violence in the relationship (Adamu, 39yrs old, divorced, + ve).

Yakubu has also identified flirting with other men as a factor for the perpetration of intimate partner violence by men in relationships.

When she goes out to sleep with other men, it is not allowed and so she must be punished either by beating, sacking her or divorce, or even reporting her to the law enforcement agencies (Yakubu, 50yrs old, married, +ve). 


\section{Theme 5: Forms of IPV}

To find out from participants whether they understand that some of the things they did or are doing to their partners were violence against them, some of them were able to identify the main forms of violence. These participants had these to say.

I understand violence to mean doing bad to my wife like insulting her, beating her, forcing to have sex with her, and not giving her money. Refusing to eat or bath with her I think is bad (Dwomo, 3lyrs old, married, -ve).

I understand violence to mean treating or handling somebody badly like beating and insulting. It can also mean refusing her things that she needs and can't get like money, sex and refusing to accompany her to the hospital (Kofi, 36yrs old, divorced, -ve).

The knowledge level of participants concerning the forms of intimate partner violence was assessed and these are some of what participants said.

The forms of violence are beating her, insulting her, refusing to give her money and looking at her with anger (Kojo, $37 y$ rs old, separated, + ve).

I realized that I was committing violence against her. Ignoring her, insulting her, refusing to sleep with her and telling people about her diagnosis as well as refusing to give her money were all forms of abuse. Other forms of abuse include slapping, beating, kicking or throwing things at her (Kwame, 37yrs, divorced, +ve).

Naba, 36 years old also identified the forms of violence in a relationship.

The forms of violence include emotional, beating, insults, psychological and ignoring and not listening to her as I used to do (Naba, 36yrs old, separated, + ve).

Ojo also said:

I later realized that refusing to touch, refusing to eat her food, divorcing her and even not sleeping with her was abuse to her................... I also know that when I beat her, insult, sack, follow her round to see if she is cheating or even taking her children away from her is abuse (Ojo, 35yrs old, divorced, -ve).

Almost all the participants were able to identify the forms of violence in one way or the other. The following are what some of them were able to identify.

Refusing to talk to her, refusing to eat, going out and coming late and maybe not buying something that will boost her morale are all forms of abuse (Salid, 39yrs, married, +ve).

Insulting her, ignoring her, telling people about her diagnosis, refusing to sleep with her and refusing to give her money where all forms of abuse.............. I thought the abuse was only when you slap, beat, kick or throw stones at a woman or somebody that we call abuse but it is not that. I regret my behaviour but I wouldn't take her back (Sarpong, 36yrs old, divorced, -ve).

The types of violence that I know are beating, insulting, force sex and refusing sex. If you also don't assist your wife in the household chores it is also a form of violence. Frowning at yourself, pushing her angrily and looking at her as if she is a child to be beaten is a form of demeaning her which is not right. Depriving her of food and sex is an abuse of her right to be fed and have sex. Life must be enjoyed by the two partners and so when that is not achieved because of one partner not allowing it then it is a form of abuse (Yakubu, 50yrs old, married, +ve).

\section{Discussion}

The objective of this study was to identify and describe the forms of IPV as well as the factors that led to the perpetration of intimate partner violence against women who were tested HIV positive by their male partners. From table 1, most of the participants had a low level of education. Low level of education is a factor for the perpetration of intimate partner violence as in Ghana and West Africa. Educational qualification is a means of getting employed in well-paid jobs. Academic qualification is said to be a source of knowledge for the individual that is utilized in many ways. Previous studies support these findings (Aol'ain, O'Rourke, \& Swaine, 2012a; Shamu, Shamu, \& Machisa, 2018). Previous studies on intimate violence (Birkley \& Eckhardt, 2015; Stith, Smith, Penn, Ward, \& Tritt, 2004) point to the fact that most violence in HIV infections is perpetrated in discordant infections but in this study, it was found that even in concordant infections perpetration of intimate partner violence was prevalent as participants argued with their partners as to who was the cause of the infection. So there were accusations and counter-accusations as to who was the first to bring the disease to the other. This led to the perpetration of violence (Afifi, Henriksen, Asmundson, \& Sareen, 2012; Birkley \& Eckhardt, 2015; Dunkle et al., 2006; Silverman et al., 2010). Anger and frustration were identified as the main emotional factors of violence as revealed by most of the participants. This is supported by Machisa, Christofides, and Jewkes (2018) when they 
found anger in relation to emotions as the cause of intimate partner violence. Other studies (Birkley \& Eckhardt, 2015; Dunkle et al., 2006; Silverman et al., 2010) also found anger as an emotional factor that can lead to violence in relationships. Anger and frustration were identified as factors that when present can lead to intimate partner violence in relationships by most of the participants. When individuals in a relationship become frustrated it leads to violence. Again, when one is angry as a result of the information from the partner that she has been infected with HIV it causes anger and frustration leading to the perpetration of intimate partner violence. These findings have been supported by Birkley and Eckhardt (2015) when they found in their study that anger and frustration were causes of intimate partner violence.

Most of the participants identified physical violence (Fleming et al., 2015) as a form of intimate partner violence and also used verbal abuse as a way to insult their partners daily especially as their relationship developed into hatred. This finding is consistent with Wilson et al. (2016) when they found that physical violence and insults were the most frequently mentioned forms of IPV in their study. Again, earlier studies (Birkley \& Eckhardt, 2015; Carney, Buttell, \& Dutton, 2007; Dunkle et al., 2006; Silverman et al., 2010; Singh, Tolman, Walton, Chermack, \& Cunningham, 2014; Stith et al., 2004) have identified physical violence as a form of intimate partner violence.

Some of the participants identified disrespect by the partner as one of the factors that made them abuse their partners which is similar to Painter (2012). Failure to assist in taking care of the children in relationships was identified as one of the factors that led to intimate partner violence. In most relationships in Ghana, the partners help each other in various ways (Apatinga \& Tenkorang, 2020; Baffoe-Whyte \& Sossou, 2019). However, in some situations, this is not done as found in this study. Some other literature has also supported this study (Anderson \& van Ee, 2018; Rakovec-Felser, 2014). Again, some of the participants revealed that their partners instead of feeling remorseful rather argued with them which led to fights. Arguments were considered a factor for perpetrating intimate partner violence. This finding is in line with Capaldi, Knoble, Shortt, and Kim (2012) in which arguments were considered a factor that led to violence. The mistrust of a partner was identified as the cause of violence. Causation of intimate partner violence was suspicion of unfaithfulness. When a partner is unfaithful, it is a problem and this, most often led to violence in the relation. This finding was supported by Nemeth, Bonomi, Lee, and Ludwin (2012) when similar findings were made in their study. In this study, it was also found that the threat of leaving a relationship was one of the factors identified as being the reason for the perpetration of intimate partner violence on a partner. Previous studies (Abrahams, Jewkes, Hoffman, \& Laubsher, 2004; Anderson \& van Ee, 2018; Dichter \& Gelles, 2012) have also made findings consistent with this study.

Most of the factors identified by participants include norms and taboos, peer influence, alcohol, drug abuse, poverty and male domination. Most of the participants also identified certain cultural practices as being the cause of intimate partner violence. Participants stated that the cultural norms and taboos of their cultures did not allow women to challenge their partners and so if this happens it creates room for abuse. This power imbalance in the family leaves the female partner vulnerable to abuse. In the Ghanaian context, men are seen as the heads of the family and so whatever they say should not be challenged (Apatinga \& Tenkorang, 2020; Dako-Gyeke et al., 2019; Dery, 2019; Owusu-Addo et al., 2018; E. Y. Tenkorang, 2019). This superior treatment of men most often leads to male dominance and dictatorship in the family as described by (Dickson et al., 2020). The feminist theories have also made their argument that defined gender roles within patriarchal societies in addition to men's systematic efforts to control women through the use of power and domination are the major causes or factors of IPV (Bell \& Naugle, 2008; Pinto et al., 2010). This finding also collaborates with Machisa et al. (2018) and Mann and Takyi (2009) when they made similar findings in their studies. Again, some of the participants identified peer influence as one of the factors that can lead to violence in intimate partner relationships (Elgar et al., 2015; Fleming et al., 2015). Most participants also stated alcohol abuse and poverty as factors that caused violence in relationships. Studies by other authors have found similar results (Machisa et al., 2018; Sabri et al., 2019; Eric Y. Tenkorang, Owusu, Yeboah, \& Bannerman, 2013) as factors that led to intimate partner violence. In most cultures, men control and dominate their partners in Ghana (Dickson et al., 2020; Issahaku, 2015; Owusu-Addo et al., 2018; E. Y. Tenkorang, 2019). Male dominance in relationships is one of the factors causing intimate partner violence in Ghana. Wife beating is a form of physical violence very common in Ghana because it is believed that the woman has no right to challenge the husband in any way whatsoever (Dickson et al., 2020). In this study, participants identified control and dominance as one of the factors that lead to violence in relationships. This finding is also consistent with some previous studies (Adjei, 2015; Asiedu \& Myers-Bowman, 2014; Collier, 2003; Javaid, 2017; Raghavan, Rajah, Gentile, Collado, \& Kavanagh, 2009).

Sex is an important factor when it comes to family life, especially with an intimate partner. It is the role of the female partners to satisfy her partner with sex in the Ghanaian context. Failure on the part of the female partner to satisfy her male partner with sex leads to conflict in the relationship which often causes violence. Again, if the 
female partner needs sex from the male partner, she may be refused if the male partner is not interested at the time. In line with this, refusing to have sex with one's partner, forcing to have sex with the partner, Suspicion of unfaithfulness and pretending to be sick to avoid sex were identified as factors that can lead to violence in the family. Again, these findings have some support from the literature with similar findings (Aol'ain, O'Rourke, \& Swaine, 2012b; Fleming et al., 2015; Frye et al., 2011; Javaid, 2017). To find out from participants whether they understand that some of the things they did or are doing to their partners were violence against them, some of them were able to identify the main forms of violence as outline in previous studies (Adjei, 2015; Aol'ain et al., 2012b; Ellsberg et al., 2015).

\section{Conclusion}

Different forms of IPV were identified by participants that were used to perpetrate violence against women who disclosed their HIV seropositive status to their male partners. These include physical violence, sexual violence, financial violence and emotional violence among others. Several factors as identified in this study accounts for this intimate partner violence. The major factors as identified in this study included emotional factors, spousal-related factors, social-related factors and sex-related factors. The identification of these forms and factors of IPV by participants is an important step in the prevention of intimate partner violence as this in itself serves as a wakeup call and an awareness creation for perpetrators because it was during the data collection process that some of the participants who were the perpetrators of IPV came to realise that they were perpetrating forms of violence against their partners. It is recommended that health care facilities heads be made aware of these identified factors so that guidelines for early detection of violence can be developed to help identify them and prevent their occurrence. It is also recommended that further research include female victims.

\section{Limitations and Strengths}

The study was done using only males which makes it difficult for the views of female victims. The strength of this study is that it has made perpetrators aware of their actions and has stimulated self-reflection of perpetration of violence against their partners.

\section{Conflict of Interest}

All the authors have declared that there was no conflict of interest.

\section{Author Contribution}

FA conceptualised and designed the study with SED and PBN. FA collected the data, did the analysis, interpreted the results and drafted the manuscript. All the authors critically reviewed the draft version of the manuscript.

\section{Competing Interests Statement}

The authors declare that there are no competing or potential conflicts of interest.

\section{References}

Abrahams, N., Jewkes, R., Hoffman, M., \& Laubsher, R. (2004). Sexual violence against intimate partners in Cape Town: prevalence and risk factors reported by men. Bulletin of the World Health Organization, 82, 330-337.

Addo-Lartey, A. A., Ogum Alangea, D., Sikweyiya, Y., Chirwa, E. D., Coker-Appiah, D., Jewkes, R., \& Adanu, R. M. K. (2019). Rural response system to prevent violence against women: methodology for a community randomised controlled trial in the central region of Ghana. Glob Health Action, 12(1), 1612604. https://doi.org/10.1080/16549716.2019.1612604

Adjei, S. B. (2015). Masculinity and Spousal Violence: Discursive Accounts of Husbands Who Abuse Their Wives in Ghana. Journal of Family Violence, 31(4), 411-422. https://doi.org/10.1007/s10896-015-9781-z

Adomako, E. B., \& Darkwa Baffour, F. (2019). Suffering in the Hands of a Loved One: The Endemic to Intimate Partner Violence and Consequences on Migrant Female Head-Load Carriers in Ghana. J Interpers Violence, 886260519888547. https://doi.org/10.1177/0886260519888547

Afifi, T. O., Henriksen, C. A., Asmundson, G. J., \& Sareen, J. (2012). Victimization and perpetration of intimate partner violence and substance use disorders in a nationally representative sample. J Nerv Ment Dis, 200(8), 684-691. https://doi.org/10.1097/NMD.0b013e3182613f64

Amegbor, P. M., Yankey, O., Rosenberg, M. W., \& Sabel, C. E. (2020). Examining Spatial Variability in the Association Between Male Partner Alcohol Misuse and Intimate Partner Violence Against Women in Ghana: A GWR Analysis. J Interpers Violence, 886260519900299. https://doi.org/10.1177/0886260519900299

Anderson, K., \& van Ee, E. (2018). Mothers and Children Exposed to Intimate Partner Violence: A Review of 
Treatment Interventions. Int J Environ Res Public Health, 15(9). https://doi.org/10.3390/ijerph15091955

Aol'ain, F. N. 1., O’Rourke, C., \& Swaine, A. (2012a). Transforming Reparations for Conflict-Related Sexual Violence: Principles and Practice. Harvard Human Rights Journal, 28, 97-146.

Aol'ain, F. N. 1., O'Rourke, C., \& Swaine, A. (2012b). Transforming Reparations for Conflict-Related Sexual Violence: Principles and Practice. Harvard Human Rights Journal, 28, 97-146.

Apatinga, G. A., \& Tenkorang, E. Y. (2020). Determinants of Sexual Violence Against Married Women: Qualitative Evidence From Ghana. Sex Abuse, 1079063220910728. https://doi.org/10.1177/1079063220910728

Asiedu, G. B., \& Myers-Bowman, K. S. (2014). Gender differences in the experiences of HIV/AIDS-related stigma: a qualitative study in Ghana. Health Care Women Int, 35(7-9), 703-727. https://doi.org/10.1080/07399332.2014.895367

Baffoe-Whyte, H., \& Sossou, M.-A. (2019). Intimate Partner Violence: The Lived Experiences of Economic and Financial Violence of Rural Women in Ghana. Partner Abuse, 10(4), 429-451. https://doi.org/10.1891/1946-6560.10.4.429

Bell, K. M., \& Naugle, A. E. (2008). Intimate partner violence theoretical considerations: moving towards a contextual framework. Clin Psychol Rev, 28(7), 1096-1107. https://doi.org/10.1016/j.cpr.2008.03.003

Birkley, E. L., \& Eckhardt, C. I. (2015). Anger, hostility, internalizing negative emotions, and intimate partner violence perpetration: A meta-analytic review. Clin Psychol Rev, 37, 40-56. https://doi.org/10.1016/j.cpr.2015.01.002

Brink, H., Walt, C. v. d., \& Rensburg, G. v. (2012). Fundamentals of Research Methodology for Healthcare Professionals (3rd ed.). South Africa: Juta \& Company Ltd.

Capaldi, D. M., Knoble, N. B., Shortt, J. W., \& Kim, H. K. (2012). A Systematic Review of Risk Factors for Intimate Partner Violence. Partner Abuse, 3(2), 231-280. https://doi.org/10.1891/1946-6560.3.2.231

Carney, M., Buttell, F., \& Dutton, D. (2007). Women who perpetrate intimate partner violence: A review of the literature with recommendations for treatment. Aggression and Violent Behavior, 12(1), 108-115. https://doi.org/10.1016/j.avb.2006.05.002

Cofie, N. (2018). A multilevel analysis of contextual risk factors for intimate partner violence in Ghana. International Review of Victimology, 26(1), 50-78. https://doi.org/10.1177/0269758018799030

Collier, R. (2003). Masculinity, Law and the Family. London and New York: Taylor \& Francis.

Dako-Gyeke, P., Addo-Lartey, A. A., Ogum Alangea, D., Sikweyiya, Y., Chirwa, E. D., Coker-Appiah, D., . . Adanu, R. M. K. (2019). 'Small small quarrels bring about happiness or love in the relationships': Exploring community perceptions and gendered norms contributing to male perpetrated intimate partner violence in the Central Region of Ghana. PLoS One, 14(11), e0225296. https://doi.org/10.1371/journal.pone.0225296

Dery, I. (2019). "Give Her a Slap or Two . . . She Might Change": Negotiating Masculinities Through Intimate Partner Violence Among Rural Ghanaian Men. Journal of Interpersonal Violence, 088626051986906. https://doi.org/10.1177/0886260519869066

Dichter, M. E., \& Gelles, R. J. (2012). Women's perceptions of safety and risk following police intervention for intimate partner violence. Violence Against Women, 18(1), 44-63. https://doi.org/10.1177/1077801212437016

Dickson, K. S., Ameyaw, E. K., \& Darteh, E. K. M. (2020). Understanding the endorsement of wife beating in Ghana: evidence of the 2014 Ghana demographic and health survey. BMC Womens Health, 20(1), 25. https://doi.org/10.1186/s12905-020-00897-8

Doat, A.-R., Negarandeh, R., \& Hasanpour, M. (2019). Disclosure of HIV Status to Children in Sub-Saharan Africa: A Systematic Review. Medicina, 55(433), 1-13. https://doi.org/10.3390/medicina55080433

Dunkle, K. L., Jewkes, R. K., Ndunad, M., Levinc, J., Jama, N., Khuzwayo, N., . . . Duvvury, N. (2006). Perpetration of partner violence and HIV risk behaviour among young men in the rural Eastern Cape, South Africa. AIDS, 20, 2107-2114.

Elgar, F. J., McKinnon, B., Walsh, S. D., Freeman, J., P, D. D., de Matos, M. G., . . Currie, C. (2015). Structural Determinants of Youth Bullying and Fighting in 79 Countries. J Adolesc Health, 57(6), 643-650. https://doi.org/10.1016/j.jadohealth.2015.08.007 
Ellsberg, M., Arango, D. J., Morton, M., Gennari, F., Kiplesund, S., Contreras, M., \& Watts, C. (2015). Prevention of violence against women and girls: what does the evidence say? The Lancet, 385(9977), 1555-1566. https://doi.org/10.1016/s0140-6736(14)61703-7

Fleming, P. J., McCleary-Sills, J., Morton, M., Levtov, R., Heilman, B., \& Barker, G. (2015). Risk factors for men's lifetime perpetration of physical violence against intimate partners: results from the international men and gender equality survey (IMAGES) in eight countries. PLoS One, 10(3), e0118639. https://doi.org/10.1371/journal.pone.0118639

Frye, V., Ompad, D., Chan, C., Koblin, B., Galea, S., \& Vlahov, D. (2011). Intimate partner violence perpetration and condom use-related factors: associations with heterosexual men's consistent condom use. AIDS Behav, 15(1), 153-162. https://doi.org/10.1007/s10461-009-9659-2

Fuseini, A. G., Afizu, A., Yakubu, Y. H., \& Nachinab, G. (2019). Facilitators to the continuous abuse of tramadol among the youth: A qualitative study in Northern Ghana. Nursing Open, 1-11. https://doi.org/10.1002/nop2.353

Issahaku, P. A. (2015). Health implications of partner violence against women in Ghana. Violence Vict, 30(2), 250-264. https://doi.org/10.1891/0886-6708.vv-d-13-00075

Javaid, A. (2017). The Unknown Victims: Hegemonic Masculinity, Masculinities, and Male Sexual Victimisation. Sociological Research Online, 22(1), 1.

Krug, E. G., Dahlberg, L. L., Mercy, J. A., Zwi, A. B., \& Lozano, R. (2002). World report on violence and health. Retrieved from Geneva:

Linos, N., Slopen, N., Subramanian, S., Berkman, L., \& Kawachi, I. (2013). Influence of community social norms on spousal violence: a population-based multilevel study of Nigerian women. American Journal of Public Health, 103(1), 148-155.

Machisa, M. T., Christofides, N., \& Jewkes, R. (2018). Social support factors associated with psychological resilience among women survivors of intimate partner violence in Gauteng, South Africa. Glob Health Action, 11(sup3), 1491114. https://doi.org/10.1080/16549716.2018.1491114

Mann, J. R., \& Takyi, B. K. (2009). Autonomy, Dependence or Culture: Examining the Impact of Resources and Socio-cultural Processes on Attitudes Towards Intimate Partner Violence in Ghana, Africa. Journal of Family Violence, 24(5), 323-335. https://doi.org/10.1007/s10896-009-9232-9

Merriam, S. B. (2009). Qualitative Research: A Guide to Design and Implementation. San Francisco: John Wiley $\&$ Sons, Inc.

Nemeth, J. M., Bonomi, A. E., Lee, M. A., \& Ludwin, J. M. (2012). Sexual infidelity as trigger for intimate partner violence. Journal of Women's Health, 21(9), 942-949.

Owusu-Addo, E., Owusu-Addo, S. B., Antoh, E. F., Sarpong, Y. A., Obeng-Okrah, K., \& Annan, G. K. (2018). Ghanaian media coverage of violence against women and girls: implications for health promotion. $B M C$ Womens Health, 18(1), 129. https://doi.org/10.1186/s12905-018-0621-1

Painter, G. R. (2012). THINKING PAST RIGHTS: TOWARDS FEMINIST THEORIES OF REPARATIONS.

Pereira, H. R. (2012). Rigour in phenomenological research: reflections of a novice nurse researcher. Nurse Researcher, 19(3), 16-19.

Pinto, L. A., Sullivan, E. L., Rosenbaum, A., Wyngarden, N., Umhau, J. C., Miller, M. W., \& Taft, C. T. (2010). Biological Correlates of Intimate Partner Violence Perpetration. Aggress Violent Behav, 15(5), 387-398. https://doi.org/10.1016/j.avb.2010.07.001

Raghavan, C., Rajah, V., Gentile, K., Collado, L., \& Kavanagh, A. M. (2009). Community Violence, Social Support Networks, Ethnic Group Differences, and Male Perpetration of Intimate Partner Violence. Journal of Interpersonal Violence, 24(10), 1615-1632.

Rakovec-Felser, Z. (2014). Domestic Violence and Abuse in Intimate Relationship from Public Health Perspective. Health Psychol Res, 2(3), 1821. https://doi.org/10.4081/hpr.2014.1821

Sabri, B., Wirtz, A. L., Ssekasanvu, J., Nonyane, B. A. S., Nalugoda, F., Kagaayi, J., . . Wagman, J. A. (2019). Intimate partner violence, HIV and sexually transmitted infections in fishing, trading and agrarian communities in Rakai, Uganda. BMC Public Health, 19(1), 594. https://doi.org/10.1186/s12889-019-6909-8

Shamu, S., Shamu, P., \& Machisa, M. (2018). Factors associated with past year physical and sexual intimate 
partner violence against women in Zimbabwe: results from a national cluster-based cross-sectional survey. Glob Health Action, 11(sup3), 1625594. https://doi.org/10.1080/16549716.2019.1625594

Silverman, J. G., Decker, M. R., McCauley, H. L., Gupta, J., Miller, E., Raj, A., \& Goldberg, A. B. (2010). Male Perpetration of Intimate Partner Violence and Involvement in Abortions and Abortion-Related Conflic. American Journal of Public Health, 100(8), 1415-1417. https://doi.org/10.2105/AJPH.2009.173393)

Singh, V., Tolman, R., Walton, M., Chermack, S., \& Cunningham, R. (2014). Characteristics of men who perpetrate intimate partner violence. $J$ Am Board Fam Med, 27(5), 661-668. https://doi.org/10.3122/jabfm.2014.05.130247

Stith, S. M., Smith, D. B., Penn, C. E., Ward, D. B., \& Tritt, D. (2004). Intimate partner physical abuse perpetration and victimization risk factors: A meta-analytic review. Aggression and Violent Behavior, 10(1), 65-98. https://doi.org/10.1016/j.avb.2003.09.001

Tenkorang, E. Y. (2019). Intimate Partner Violence and the Sexual and Reproductive Health Outcomes of Women in Ghana. Health Educ Behav, 46(6), 969-980. https://doi.org/10.1177/1090198119859420

Tenkorang, E. Y., Asamoah-Boaheng, M., \& Owusu, A. Y. (2020). Intimate Partner Violence (IPV) Against HIV-Positive Women in Sub-Saharan Africa: A Mixed-Method Systematic Review and Meta-Analysis. Trauma Violence Abuse, 1524838020906560. https://doi.org/10.1177/1524838020906560

Tenkorang, E. Y., Owusu, A. Y., Yeboah, E. H., \& Bannerman, R. (2013). Factors Influencing Domestic and Marital Violence against Women in Ghana. Journal of Family Violence, 28(8), 771-781. https://doi.org/10.1007/s10896-013-9543-8

Watts, C., \& Zimmerman, C. (2002). Violence against women: global scope and magnitude. The lancet, 359(9313), 1232-1237. https://doi.org/10.1016/s0140-6736(02)08221-1

Wilson, K. S., Wanje, G., Yuhas, K., Simoni, J. M., Masese, L., Vander Stoep, A., . . Scott McClelland, R. (2016). A Prospective Study of Intimate Partner Violence as a Risk Factor for Detectable Plasma Viral Load in HIV-Positive Women Engaged in Transactional Sex in Mombasa, Kenya. AIDS Behav, 20(9), 2065-2077. https://doi.org/10.1007/s10461-016-1420-z

Smith, T., Scahill, L., Dawson, G., Guthrie, D., Lord, C., \& Odom, S. (2007). Designing research studies on psychosocial interventions in autism. Journal of Autism and Developmental Disorders, 37(2), 354-366. https://doi.org/10.1007/s10803-006-0173-3

\section{Copyrights}

Copyright for this article is retained by the author(s), with first publication rights granted to the journal.

This is an open-access article distributed under the terms and conditions of the Creative Commons Attribution license (http://creativecommons.org/licenses/by/4.0/). 